Cite this: Phys. Chem. Chem. Phys., 2013,

\title{
Synthesis and photophysics of novel biocompatible fluorescent oxocines and azocines in aqueous solution $\dagger$
}

15, 16704

Received 27th May 2013,

Accepted 29th July 2013

DOI: $10.1039 / \mathrm{c} 3 \mathrm{cp} 52228 \mathrm{~h}$

www.rsc.org/pccp

\author{
A. Ulises Acuña, ${ }^{* a}$ Mónica Álvarez-Pérez, ${ }^{a}$ Marta Liras, ${ }^{b}$ Pedro B. Coto ${ }^{c}$ and \\ Francisco Amat-Guerrił ${ }^{\mathrm{b}}$
}

\section{Introduction}

The recent developments in fluorescence-based analytical and imaging techniques resulted in unprecedented improvements in detection sensitivity and spatial resolution, as well as in the diversity of samples that may be quantitatively studied with optical techniques, from a single molecule ${ }^{1}$ to a living organism. ${ }^{2}$

\footnotetext{
a Instituto de Química Física "Rocasolano", C.S.I.C., Serrano 119, 28006 Madrid, Spain. E-mail: roculises@iqfr.csic.es; Fax: +34 91 5642431; Tel: +34 917459501

${ }^{b}$ Instituto de Quimica Orgánica General, C.S.I.C., Juan de la Cierva 3, 28006 Madrid, Spain

${ }^{c}$ Departamento de Quimica I, Universidad de Alcalá, E-28871, Alcalá de Henares (Madrid), Spain

$\dagger$ Electronic supplementary information (ESI) available: (1) General experimental methods, (2) synthesis, purification and chemical characterization of oxocines $\mathbf{1 a , b}$ and azocines $\mathbf{2 a , b}, \mathbf{b}$, (3) reaction optimization and mechanism, (4) sample titration plots of 1a and absorption and emission spectra of $\mathbf{1 b}$, (5) NMR spectra of products, (6) computational details: molecular orbitals, transition dipole components, relative triplet energies and cartesian coordinates of oxo- and azacompounds. See DOI: $10.1039 / \mathrm{c} 3 \mathrm{cp} 52228 \mathrm{~h}$

† Deceased on November 2011.
}

Successful application of these advances depends on the availability of fluorescent labels and probes with specific properties, ${ }^{3}$ and on efficient methods of targeting fluorescent labeling. ${ }^{4}$ Here we report the synthesis and main photophysical properties of a novel fluorescent molecular platform, which displays several convenient features for these applications: (i) $100 \%$ emission quantum yield in aqueous solution, (ii) pH-dependent switching between bright "on" and dark "off" states and (iii) full compatibility with biological media.

The origin of the new emitting materials is related to the first reference to fluorescence (1565) credited to N. Monardes, a physician from Seville (Spain) who noted the strange "color" of the infusion of an American medicinal wood of uncertain genealogy. ${ }^{5}$ It has been shown recently that the wood was obtained from a Mexican tree (Eysenhardtia polystachya (Ort.) Sarg.) very rich in a rare glucosyl-dihydrochalcone, ${ }^{6}$ which is non-fluorescent. However, as soon as the non-emitting dihydrochalcone passes from the wood to water solution, a fast oxidation reaction takes place to yield a strongly fluorescent glucoside (matlaline, $\phi_{\mathrm{F}}=1.0$ ), the source of the unusual "color" of the old 

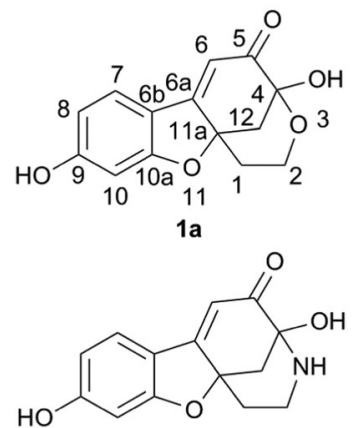

2a
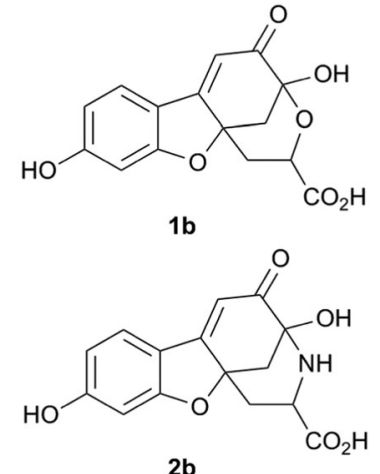

2b
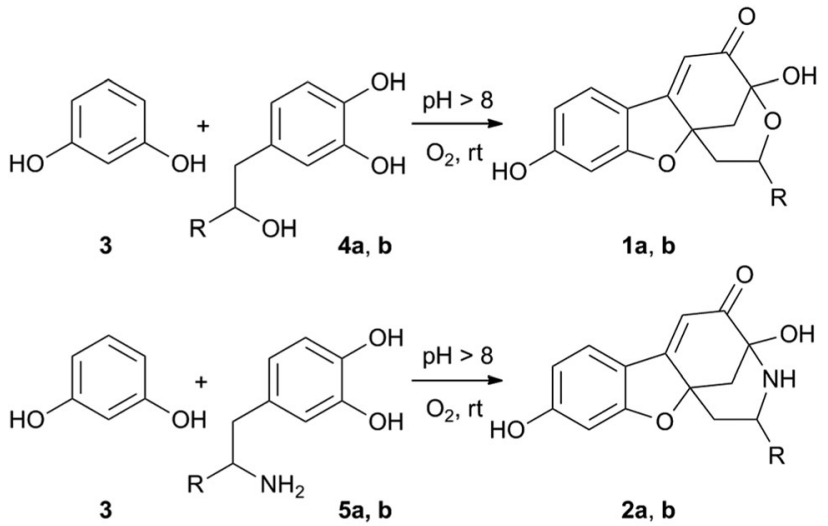

$\mathrm{R}=\mathrm{H}(\mathbf{a}), \mathrm{CO}_{2} \mathrm{H}(\mathbf{b})$
Fig 1 Chemical structure of monardine (MON, 1a), carboxymonardine (CMON 1b), azamonardine (AZMON, 2a) and carboxyazamonardine (CAZMON, 2b).

medicinal infusion. ${ }^{7}$ The glucosilated fluorophore was found to be preformed in another tree (Pterocarpus indicus Willd.) from the Philippine Islands. ${ }^{7}$ The unusual four-ring structure of the natural dye was confirmed by reproducing the intramolecular oxidation reaction with a synthetic dihydrochalcone analog, ${ }^{7}$ which yielded the dye fluorescent core 1a (Fig. 1).

Recently, we discovered that $\mathbf{1 a}$, as well as a new family of strongly fluorescent oxocines, can also be prepared from catechols (o-diphenol compounds) by a simple, one-step bimolecular reaction in water solution at room temperature. This is an example of a fluorogenic reaction ${ }^{8}$ in which a non-emissive or weakly UV-emitting compound (catechol) is quickly converted into a bright VIS-emitting product. Moreover, monoamine o-diphenol compounds (aminocatechols) of biological relevance, such as the neurotransmitter dopamine and the amino acid DOPA (3-(3,4dihydroxyphenyl)-rac-alanine), also undergo the fluorogenic reaction. Remarkably, the four-ring fluorescent azocine product of DOPA reaction ( $2 \mathbf{b})$ had been identified previously in a detailed investigation of oxidative transformation of $o$-quinones, a process related to melanogenesis and insect cuticle sclerotization. ${ }^{9}$

Here we describe in detail the fluorogenic reactions of prototype catechols (hydroxytyrosol and salvianic acid) and aminocatechols (dopamine and DOPA), as well as the spectroscopic characterization of the corresponding fluorescent products (Fig. 1): monardine ${ }^{10}(\mathbf{1 a})$, carboxymonardine (1b), azamonardine (2a) and carboxyazamonardine (2b). The pH-dependent spectral properties and fluorescence polarization data of these compounds are reported, and an attempt is made to interpret the absorption and emission experimental observations of the different prototropic species in terms of the corresponding large changes in singlet and triplet excited-state distribution, as computed by TDDFT quantum chemical methods.

\section{Experimental}

\section{Chemical methods}

Oxocines 4,9-dihydroxy-1,2-dihydro-4,11a-methanooxocino[4,5- $b]$ benzofuran-5(4H)-one (1a, monardine) and 4,9-dihydroxy-5-oxo1,2,4,5-tetrahydro-4,11a-methanooxocino[4,5- $b]$ benzofuran-2carboxylic acid (2a, carboxymonardine) were obtained through
Scheme 1 Synthesis of monardine (1a), azamonardine (2a) and the corresponding carboxy-substituted derivatives. Reagents and conditions: equimolar quantities of 1,3-dihydroxybenzene (resorcinol, 3) and the corresponding 1,2-dihydroxybenzene derivative (catechols 4 or aminocatechols 5 ) were dissolved in alkaline water $(\mathrm{pH} 8-11)$ in the presence of air at room temperature. See ESIt for a detailed description of synthetic procedures.

reaction of resorcinol (3) with hydroxytyrosol (4a) or salvianic acid (4b), respectively, in alkaline water solution (Scheme 1). A similar reaction with dopamine (5a) or DOPA (5b) yielded the corresponding azocines 4,9-dihydroxy-3,4-dihydro- $1 H-4,11 \mathrm{a}-$ methanobenzofuro[2,3- $d$ ] azocin-5(2H)-one (2a, azamonardine) or 4,9-dihydroxy-5-oxo-2,3,4,5-tetrahydro- $1 H$-4,11a-methanobenzofuro$[2,3-d]$ azocine-2-carboxylic acid (2b, carboxyazamonardine). Solvent and reactant sources, reaction conditions, isolation and full chemical characterization of the fluorescent reaction products may be found in the ESI. $\dagger$

\section{Spectroscopic methods}

Steady-state fluorescence excitation, emission and polarization spectra were recorded using a photon-counting PC1 fluorometer (ISS, US). All spectra and wavelengths shown here pertain to corrected spectra. Instrument correction factors were determined in-house using a Rhodamine B quantum counter ${ }^{11}$ and a calibrated tungsten-ribbon radiance source for the excitation and emission channels, respectively. Emission anisotropy values were computed from polarized intensities and corrected as described elsewhere. ${ }^{12}$ Apparent ionization constants $\mathrm{p} K_{\mathrm{a}}$ were determined from absorption and/or fluorescence intensity titration ${ }^{13}$ in the $2-12 \mathrm{pH}$ range, using dilute water solutions of the "universal" Britton-Robinson buffer containing mixtures of sodium salts of acetic, boric and phosphoric acids. ${ }^{14}$ Time-resolved fluorescence data were acquired by the time-correlated single-photon counting technique, exciting the samples at 375 or $407 \mathrm{~nm}$ with pulsed diode lasers (PicoQuant $\mathrm{GmbH}$, Germany) at an $8 \mathrm{MHz}$ repetition rate. The instrument response function of the detection channel, that included a $10 \mathrm{~cm}$ monochromator and a R1564U microchannelplate photomultiplier (Hamamatsu Photonics, Japan), was $\sim 70$ ps. Decay traces were analyzed as multiexponential functions by NLLS methods, using the Globals software package developed at the Fluorescence Dynamics Laboratory, Univ. of Illinois, Urbana-Champaign (U.S.). 
The fitting function was considered adequate if a minimum of variable parameters yielded $\chi^{2}$ values in the $0.9-1.2$ range and a random distribution of weighted residuals. Nanosecond fluorescence lifetimes are given with 0.05 ns uncertainty. See $\mathrm{ESI} \dagger$ for additional technical details.

\section{Computational methods}

The systems investigated in this work have been modeled using density functional theory (DFT). Ground-state equilibrium structures of the different molecules were computed using the HSE06 functional ${ }^{15}$ and Pople's $6-31++G(d, p)$ basis set. Solvation effects have been simulated by including the integral equation formalism of the polarizable continuum model (PCM) ${ }^{16}$ using $\mathrm{H}_{2} \mathrm{O}$ as solvent. Vertical excitation energies of the lowest-lying singlet and triplet states have been computed by time dependent density functional theory (TDDFT), using the HSE06 correlation-exchange functional and the $6-311++G(d, p)$ basis set to get a balanced description of low-lying valence and Rydberg states. Since this functional was not designed for the description of charge transfer states, the possible impact of these states in the above computations was investigated using specific correlation-exchange functionals designed for this purpose (see ESI $\dagger$ ). The effect of solvent on excitation energies was incorporated by means of the PCM approach within the linear response (LR) version of the TDDFT method. ${ }^{17}$ All the calculations have been carried out using Gaussian09 program package. ${ }^{18}$

\section{Results}

\section{Absorption and emission properties of monardine (1a) and carboxymonardine (1b)}

Monardine (1a) is virtually the sole product at short reaction times of the fast oxidative coupling between resorcinol and hydroxytyrosol (Scheme 1), using atmospheric oxygen as the oxidant. The absorption spectrum of $\mathbf{1 a}$ in slightly alkaline water solution displays an intense, structureless absorption band at $425.5 \mathrm{~nm}$ (Fig. 2 and Table 1), that is blue-shifted to $382 \mathrm{~nm}$ in a reversible way in acidic solution, with a large decrease in the absorption coefficient (Table 1). These changes in absorption spectra are assigned to a prototropic equilibrium between neutral (N) and anionic (A) forms, due to ionization of the OH-group at position 9, as discussed below. The two species are chemically and photochemically stable in the 3-12 $\mathrm{pH}$ range.

The anionic form shows a strong blue fluorescence, peaking at $464 \mathrm{~nm}$, with a Stokes shift of $\sim 2000 \mathrm{~cm}^{-1}$ and a quantum yield $\phi_{\mathrm{F}}=1.0 \pm 0.1$, while the neutral form is very weakly emissive (Fig. 2 and Table 1). As expected, the shape of the anion fluorescence band is a mirror image of the absorption one. Absorption and fluorimetric titrations yielded the same value for the prototropic equilibrium constant: $\mathrm{p} K_{\mathrm{a}}=7.2 \pm 0.4$, $20{ }^{\circ} \mathrm{C}$ (see Fig. S1 of the ESI $\dagger$ for sample titrations). The fluorescence parameters of monardine listed in Table 1 were obtained at $\mathrm{pH}$ values where the excitation and emission spectra are independent of the emission-excitation wavelengths, indicating that a single molecular species populates the ground state; the anion fluorescence decay is accurately

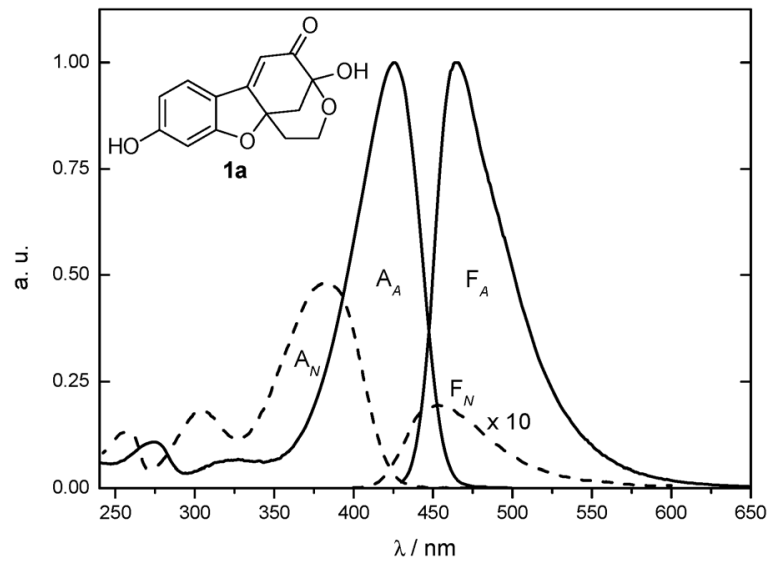

Fig. 2 Absorption and fluorescence spectra of neutral (N) and anionic (A) forms of monardine, $\mathbf{1} \mathbf{a}$, in aqueous solution. $\mathbf{A}_{\mathbf{N}}$ and $\mathbf{F}_{\mathbf{N}}$ : absorption and corrected fluorescence spectra of the neutral species at $\mathrm{pH}$ 4. $\mathrm{A}_{\mathrm{A}}$ and $\mathrm{F}_{\mathrm{A}}$ : the corresponding spectra of the monoanion species from the same solution at $\mathrm{pH} 9$. [1a] $\approx$ $2 \times 10^{-6} \mathrm{M}, \lambda_{\text {exc }}=425 \pm 2 \mathrm{~nm}, T=20^{\circ} \mathrm{C}$.

monoexponential, with a lifetime of 2.74 ns. Preliminary experiments indicated that the monardine anion also presents a large two-photon fluorescence excitation cross-section, with $\lambda_{\max } \sim 400 \mathrm{~nm}$. The two-exponential fit of the neutral form weak emission yields a $\sim 70$ ps major component (99.9\%), limited by the time resolution of our methods, and a residual $(<0.1 \%)$ slower decaying component $(2.7 \mathrm{~ns})$.

The reaction between resorcinol and salvianic acid (Scheme 1) also proceeds quickly to yield carboxymonardine, (1b), as a major reaction product. The spectroscopic properties in acidic and alkaline solution, as well as the $\mathrm{p} K_{\mathrm{a}}$ value, iterate those of the unsubstituted chromophore (Table 1 and Fig. S2 of the ESI $\dagger$ ). In alkaline solution ( $\mathrm{pH}$ 9) carboxymonardine (1b) should be in dianionic form, due to the ionization of both the 9-OH and 2-COOH groups. However, neither the carboxylic nor the carboxylate groups affect the spectral properties of the neutral and dianionic forms, which remain virtually identical to those of the unsubstituted dye $\mathbf{1 a}$.

Polarized fluorescence excitation and emission spectra of the carboxymonardine dianion in alkaline glycerol at low temperature $\left(5{ }^{\circ} \mathrm{C}\right)$ are presented in Fig. 3 and 4 . Compound 1b was selected for these experiments, instead of the parent dye 1a, to decrease further re-orientational motions within the highly viscous glycerol matrix. The $380-460 \mathrm{~nm}$ range corresponds to the $\mathrm{S}_{0}-\mathrm{S}_{1}$ absorption band, approximately, with an average anisotropy value $r_{\mathrm{ss}}=0.383 \pm 0.006$ very close to the one-photon theoretical $2 / 5$ value for coincident absorption and emission transition moments. Instrument and sample-dependent factors may account for this small discrepancy. ${ }^{19}$

\section{Absorption and emission properties of azamonardine (2a) and carboxyazamonardine $(2 \mathrm{~b})$}

The reaction of resorcinol with dopamine and DOPA yields 2 a and $\mathbf{2 b}$, respectively, the aza-analogues of $\mathbf{1 a}, \mathbf{b}$, which are also fluorescent. The spectroscopic properties of these compounds depend on solution $\mathrm{pH}$ in a more complex way than in the 
Table 1 Absorption and fluorescence properties of monardine (1a, MON), carboxymonardine (1b, CMON), azamonardine (2a, AZMON) and carboxyazamonardine (2b, CAZMON) in water solution as a function of $\mathrm{pH}^{\mathrm{a}}$

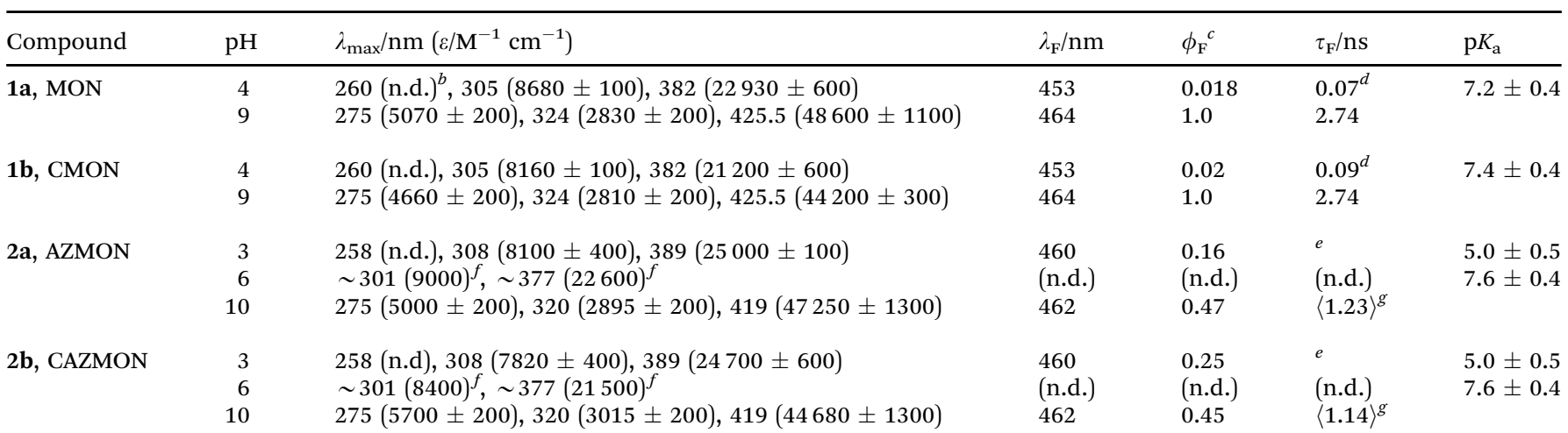

${ }^{a} \mathrm{p} K_{\mathrm{a}}$ : apparent ioniz. constant. ${ }^{b}$ Not determined. ${ }^{c} \pm 10 \% .{ }^{d}$ Major component $(99.9 \%) .{ }^{e}$ See Table $2 .{ }^{f}$ Estimated values of the (N) form. ${ }^{g}\langle\tau\rangle=\sum a_{i} \tau_{i}$

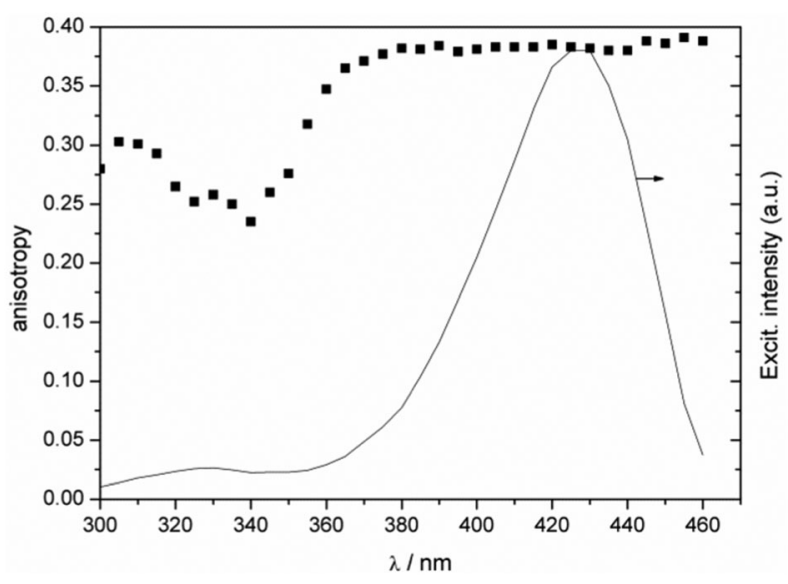

Fig. 3 Corrected fluorescence excitation intensity (-) and anisotropy spectra of carboxymonardine (1 $\mathbf{b})$ dianion in $99.5 \%$ alkaline glycerol solution at $2 \times 10^{-6} \mathrm{M}, \mathrm{pH} \approx 10, \lambda_{\mathrm{em}}=470 \pm 4 \mathrm{~nm}, T=5^{\circ} \mathrm{C}$.

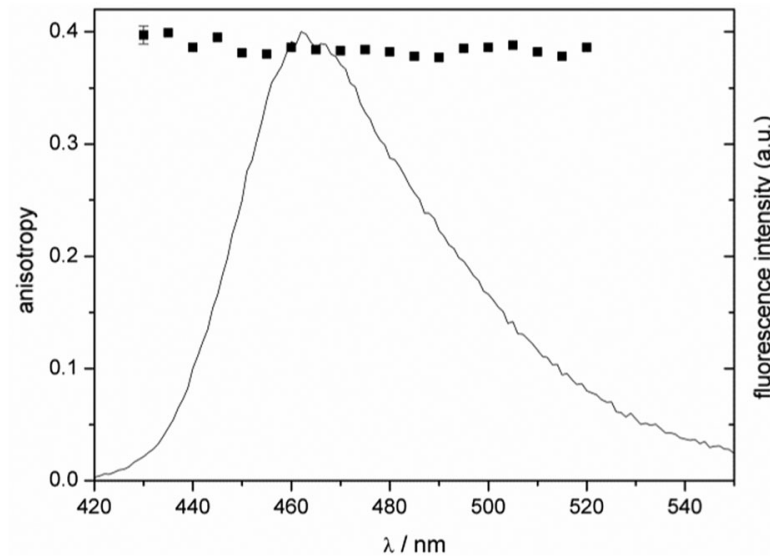

Fig. 4 Corrected fluorescence emission intensity (-) and anisotropy ( $\mathbf{\square})$ spectra of carboxymonardine (1b) dianion in $99.5 \%$ alkaline glycerol solution at $2 \times$ $10^{-6} \mathrm{M}, \mathrm{pH} \approx 10, \lambda_{\mathrm{exc}}=420 \pm 1 \mathrm{~nm}, T=5^{\circ} \mathrm{C}$.

oxo-chromophore. In acidic solution (pH 4) the shape of the absorption spectrum of azamonardine (2a) is very similar to

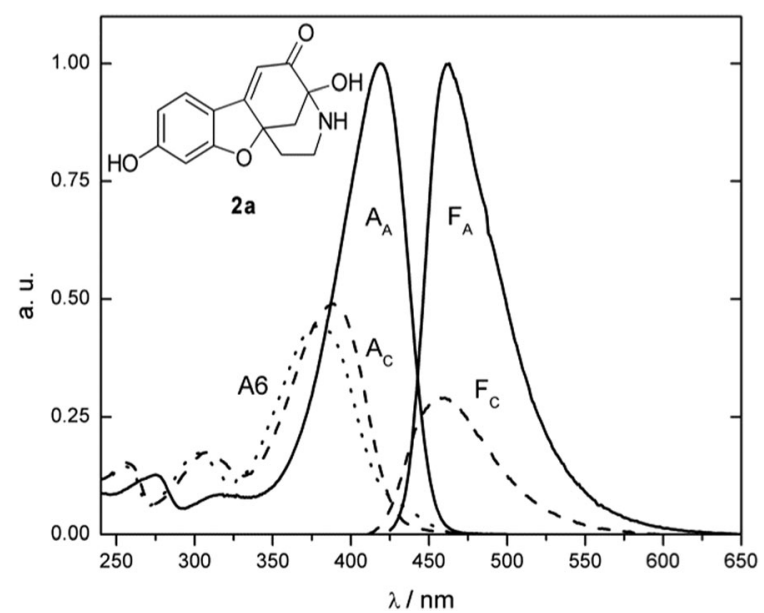

Fig. 5 Absorption and fluorescence spectra of different prototropic forms of azamonardine (2a) in aqueous solution. $\mathbf{A}_{\mathbf{c}}$ and $\mathbf{F}_{\mathbf{c}}$ : absorption and fluorescence spectra of the cationic species at $\mathrm{pH}$ 4. $\mathbf{A 6}$ : absorption spectrum at pH 6. $\mathbf{A}_{\mathbf{A}}$ and $\mathrm{F}_{\mathrm{A}}$ : absorption and fluorescence spectra of the anionic species at $\mathrm{pH} 9 \cdot[2 \mathrm{a}] \approx$ $10^{-6} \mathrm{M}, \lambda_{\text {exc }}=389$ (cation), $419 \mathrm{~nm}$ (anion) $\pm 2 \mathrm{~nm}, T=20^{\circ} \mathrm{C}$.

that of monardine neutral form (Table 1 and Fig. 5) but slightly red-shifted. Approaching neutral solution $(\sim \mathrm{pH} 6)$ the absorption spectrum shifts to the blue, with small changes in the band shape and the absorption coefficient (Fig. 5), indicating the presence of a new species in the ground state. Finally, at pH 9-10 an intense absorption band at $419 \mathrm{~nm}$ dominates the spectrum, with the shape and the absorption coefficient similar to those of monardine anionic form. This anion form is strongly fluorescent, with a quantum yield of $\sim 50 \%$ (Table 1 ). These spectral changes are fully reversible and were assigned to different prototropic forms of the aza-compound as discussed below, i.e., to cationic (C), neutral (N) and monoanion (A) forms of 2a. The spectroscopic parameters of the neutral form cannot be determined with accuracy due to the large overlap with the corresponding spectra of the cationic and anionic species. Nevertheless, it was found that both cationic and neutral forms are fluorescent (Fig. 5), with $\phi_{\mathrm{F}}(\mathbf{N}) \approx 3 \phi_{\mathrm{F}}(\mathbf{C})$. Two macroscopic $\mathrm{p} K_{\mathrm{a}}$ values 
Table 2 Time-resolved fluorescence decay of azamonardine (2a) and carboxyazamonardine (2b) in acidic and alkaline aqueous solution ${ }^{a}$

\begin{tabular}{lrllllllll}
\hline Compound & $\mathrm{pH}$ & $\lambda_{\text {exc }}$ & $\lambda_{\mathrm{em}}$ & $a_{1}$ & $a_{2}$ & $a_{3}$ & $\tau_{1}$ & $\tau_{2}$ & $\tau_{3}$ \\
\hline 2a, AZMON & 3 & 375 & 460 & -0.2 & 0.78 & 0.02 & 0.22 & 0.5 & 2.5 \\
& 10 & 407 & 470 & 0.77 & 0.23 & & 1.04 & 1.86 & \\
2b, CAZMON & 3 & 375 & 460 & -0.2 & 0.77 & 0.03 & 0.24 & 0.67 & 2.1 \\
& 10 & 407 & 470 & 0.52 & 0.48 & & 0.8 & 1.5 &
\end{tabular}

${ }^{a}$ Uncertainty of pre-exponential factors and lifetimes (ns) $\sim 10 \%$.

could be estimated from absorption and/or fluorescence titrations, with different levels of uncertainty, as shown in Table 1.

The time-resolved analysis of the emission of the protonated and anionic forms of 2a indicates a complex excited-state behavior (Table 2). Fitting the emission decay in acidic solution at $\mathrm{pH} 3$ (cationic species) required a numerical model with a rise-time component and two decay times (Table 2); in addition, the decay of monoanion fluorescence in alkaline solution ( $\mathrm{pH} 10)$ is clearly biexponential. The analysis of the emission at nearneutral $\mathrm{pH}$ is further complicated by the simultaneous presence of all prototropic forms, and was not investigated further.

Carboxyazamonardine (2b) spectral properties depend on $\mathrm{pH}$ in the same way as those of the unsubstituted dye, and three prototropic absorbing species can also be postulated. These properties, listed in Tables 1 and 2, are also virtually identical to those of the unsubstituted dye $\mathbf{2 a}$, apart from some differences in the fluorescence lifetime of the dianion species.

\section{Discussion}

\section{Monardine prototropic species}

The fluorogenic reaction between hydroxytyrosol and resorcinol yields 1a, a very stable aromatic hemiacetal characterized by large changes in absorption and emission properties as a function of solution $\mathrm{pH}$. The highly fluorescent species giving rise to the intense absorption at $425.5 \mathrm{~nm}$ is most likely the phenolate anion (A) formed by ionization of the 9-OH group of the neutral species $\mathbf{N}$ (Fig. 6) as in the related compound matlaline, ${ }^{7}$ since compound 1a does not contain alternative ionizable groups in the near-neutral $\mathrm{pH}$ range. The experimental $\mathrm{p} K_{\mathrm{a}}$ value (7.2) of the neutral species (Table 1) is comparable to

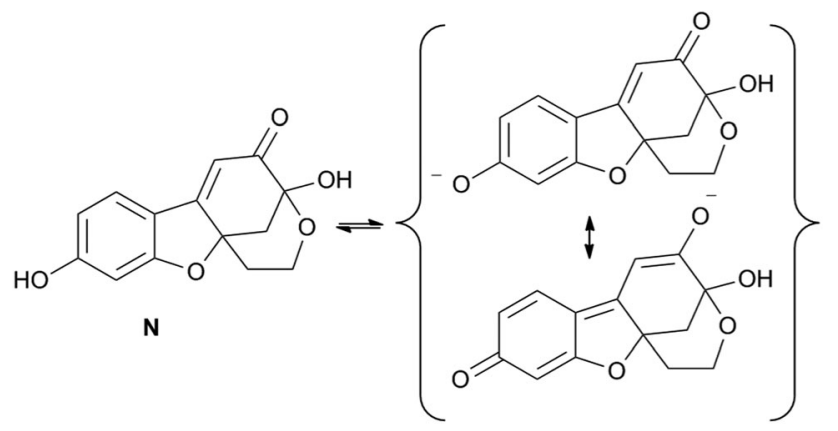

A

Fig. 6 Neutral (N) and anionic (A) species of monardine (1a) in aqueous solution. that of substituted 7-OH coumarins, ${ }^{20}$ and the electronic factors giving rise to the increased acidity of the 9-OH phenol group, as compared to that of simpler monophenol compounds, are also expected to be similar. ${ }^{21}$ Interestingly, monardine ionization equilibrium provides a fluorescence equivalent to a binary switch. ${ }^{22}$

\section{Monardine electronic transitions and photophysics}

Theoretical values of singlet and triplet relative energies and vertical electronic transitions for the neutral and anionic forms of the dye were estimated by quantum-chemical computations at the TDDFT level (HESE06/6-311++G(d,p)//HSE06/6-31++G(d,p)). As indicated above, the aqueous environment was simulated using the PCM approximation. In this way, specific dye-water interactions (which should be more important for the anionic species) have not been considered. The calculated geometrical parameters of ground-state monardine (1a, 4S, 11aS) (Fig. 7 and $\mathrm{ESI} \dagger$ ) agree quite well with the corresponding experimental bond distances and angles determined from the single-crystal X-ray structure of $\mathbf{1 b}$ methyl ester. ${ }^{7}$ The molecular plane defined by the phenyl and furanyl rings deviates very little $\left(\sim 10^{\circ}\right)$ from that defined by the $\mathrm{C} 6 \mathrm{a}=\mathrm{C} 6$ double bond and the carbonyl group.

The deviation from coplanarity is even lower for the anion species $\left(\sim 8^{\circ}\right)$, facilitating the formation of a $\pi$-electron conjugated system extending over the whole molecule. Bond distances $\mathrm{C} 7-\mathrm{C} 8$ and $\mathrm{C} 10 \mathrm{a}-\mathrm{C} 10$ are shorter than other $\mathrm{C}-\mathrm{C}$ bond lengths in the phenyl ring, indicating a quinoid character of this cycle ${ }^{23}$ which increased in the anion form (Fig. 6). The molecular framework is very rigid, due to the locking effect of the tetrahedral carbon atom C12, among other factors.

The relative energy and electronic character of the five lowest lying singlet and triplet states of neutral monardine, computed as detailed above, are shown in Table 3. The maximum of the first experimental absorption band (382 nm, $3.25 \mathrm{eV}$ ) compares reasonably well with the optically allowed vertical excitation to the $\mathrm{S}_{1}$ state, represented mostly by a HOMO $\rightarrow \operatorname{LUMO}\left(\pi, \pi^{*}\right)$ transition. Excitation to the $S_{2}$ state, nearly degenerated with $S_{1}$ within the accuracy of the method, is optically forbidden due to the dominant HOMO - $1 \rightarrow$ LUMO ( $\left.\mathrm{n}, \pi^{*}\right)$ transition (see ESI + ). The remaining absorption bands, observed at $305 \mathrm{~nm}(4.07 \mathrm{eV})$ and $260 \mathrm{~nm}$ (4.77), correspond nicely with the excitation energy and character of $\mathrm{S}_{3}$ and $\mathrm{S}_{5}$ (Table 3). In the triplet manifold two different states $T_{2}\left(\pi, \pi^{*}\right)$ and $T_{3}\left(n, \pi^{*}\right)$ are located very close in energy to the lowest $\mathrm{S}_{1}$ and $\mathrm{S}_{2}$ states. According to the experimental observations, the lowest-lying excited singlet of the neutral species in aqueous solution is very efficiently deactivated. Vibronic interactions between close-lying $S_{1}\left(\pi, \pi^{*}\right)$ and $S_{2}\left(n, \pi^{*}\right)$ states would enhance
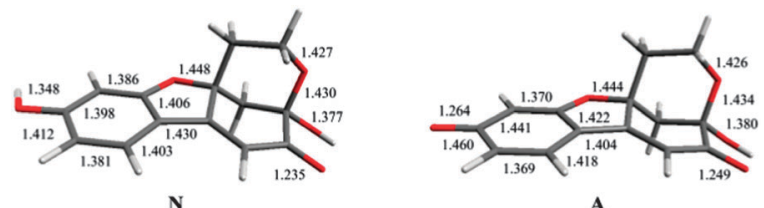

A

Fig. 7 Optimized geometry of ground-state neutral and anionic forms of monardine (1a, 4S, 11aS). 


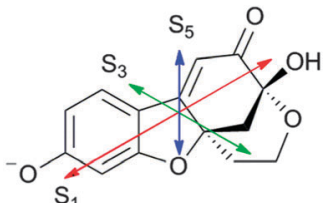

Fig. 8 Orientation of the transition dipole moment of the lowest-lying $\left(\pi, \pi^{\star}\right)$ excitations in monardine anion.

the rate of intersystem crossing to nearby triplet states, ${ }^{24}$ further favored by spin-orbit coupling between singlet and triplet states of different electronic symmetry, ${ }^{25}$ as well as other radiationless processes. As a result of that the fluorescence of neutral monardine would be largely suppressed.

In the anion species, the large changes in the absorption spectrum are also well reproduced by the computed data (Table 3). The intense absorption at $426 \mathrm{~nm}(2.9 \mathrm{eV})$ can be assigned to excitation to the optically allowed $S_{1}\left(\pi, \pi^{*}\right)$ state $(3.3 \mathrm{eV})$, which in the anion is stabilized relative to the $\mathrm{S}_{2}\left(\mathrm{n}, \pi^{*}\right)$ state preventing interstate coupling. Note that the calculated $\mathrm{S}_{1}$ energy is overestimated due to the known limitations of the PCM approach in accounting for specific solvation effects of the charged phenolate species. The weak absorption bands at $320 \mathrm{~nm}(3.8 \mathrm{eV})$ and $275 \mathrm{~nm}(4.5 \mathrm{eV})$ are assigned to excitation to $S_{3}\left(\pi, \pi^{*}\right)$ and $S_{5}\left(\pi, \pi^{*}\right)$ states, respectively, which also show a reduced oscillator strength. This assignment is also consistent with the anion fluorescence excitation anisotropy spectrum depicted in Fig. 3. According to the computed data (Table S1, ESI $\dagger$ ), the $\mathrm{S}_{0}-\mathrm{S}_{1}$ transition moment is essentially contained within the molecular plane, as defined above, and aligned with the long molecular axis, while transition moments $\mathrm{S}_{0}-\mathrm{S}_{3}$ and $\mathrm{S}_{0}-\mathrm{S}_{5}$ are oriented $+61^{\circ}$ and $-60^{\circ}$ relative to $\mathrm{S}_{1}$, and also mostly included in that plane, as illustrated in Fig. 8. The spectrum of Fig. 3 shows an important decrease of anisotropy by excitation in the $320 \mathrm{~nm}$ range $\left(\mathrm{S}_{3}\right)$, not as large as expected due probably to vibrational coupling of this weakly allowed state or to overlap with high vibrational states of $\mathrm{S}_{1}$. The high fluorescence efficiency of the anion is associated to the $S_{1}\left(\pi, \pi^{*}\right)$ excited state, with large oscillator strength and well separated from the nearest $\left(n, \pi^{*}\right)$ state, and to a very rigid molecular framework. In addition, the unusual distribution of triplet states (Table 3) is likely the crucial factor behind the $100 \%$ emission efficiency. There is a large energy gap between $S_{1}$ and $T_{1}$, which are of the same electronic configuration, while the closely grouped $\mathrm{T}_{2}-\mathrm{T}_{5}$ states are expected to be located at higher energy than the solvent-relaxed emitting state. As a result of that the intersystem crossing rate becomes negligible.

It was shown above that the carboxy-substituted compound 1b displays identical spectral properties and $\mathrm{pH}$-dependent changes as 1a. The covalent binding of dyes to biomolecules is frequently achieved by the reaction of amino or sulfhydryl groups of the target compound with functionalized dye derivatives. Therefore, the carboxylic group at position 2 in $\mathbf{1 b}$ appears as an ideal point to attach a reacting handle while preserving the favorable spectral properties of the dye. The saturated structure of this part of the molecule very effectively 
isolates the $\pi$ conjugated system from intramolecular electronic interactions.

\section{Azamonardine prototropic species}

Dopamine and DOPA yield the aza-analogues of monardine 2a and $\mathbf{2 b}$ (Fig. 1). The carboxy-substituted compound $\mathbf{2 b}$ was first isolated and identified by Crescenci $e t a l{ }^{9}$ in a study of the mechanism of the melanogenesis reaction in vitro, as mentioned above. These authors also noted the fluorescence of the novel compound which, presumably, was a mixture of $\mathbf{2 b}$ prototropic species.

The overall features of the absorption and emission spectra of azamonardine in the 4-9 $\mathrm{pH}$ range are similar to those of monardine (Fig. 5 and Table 1); there is also a strongly absorbing species under near-neutral conditions $\left(\mathrm{p} K_{\mathrm{a}}=7.6\right)$ with high fluorescence quantum yield $\sim 0.5$ (Table 1 ). On the other side, the detailed emission properties of azamonardine are much more complex than those of the oxo-compound. Thus, in the $\mathrm{pH}$ range 4-6 a protolytic equilibrium between two species with a similar absorption spectrum can be detected (Fig. 5). The species appearing near $\mathrm{pH} 4$ is very likely the cationic form of 2a (C in Fig. 9) with a protonated amino group. This species is fluorescent, with a quantum yield of 0.16 and an emission spectrum similar to that of the anionic form (Table 1 and Fig. 5). Increasing solution $\mathrm{pH}$ yields a new blue-shifted absorbing species which is also fluorescent, tentatively assigned to the neutral form $\mathbf{N}(\mathbf{1})\left(\mathrm{p} K_{\mathrm{a}} \approx 5\right)$ shown in Fig. 9, in which the 9-OH group is not ionized. This assignment is based on the absence of the intense red-shifted absorption band characteristic of the phenolate group, although a zwitterionic form $\mathbf{N}(2)$ cannot be ruled out. In fact, the emission spectrum (not shown) and quantum yield $(\approx 0.4)$ of the neutral form are very similar to those of the anionic species. These observations may be

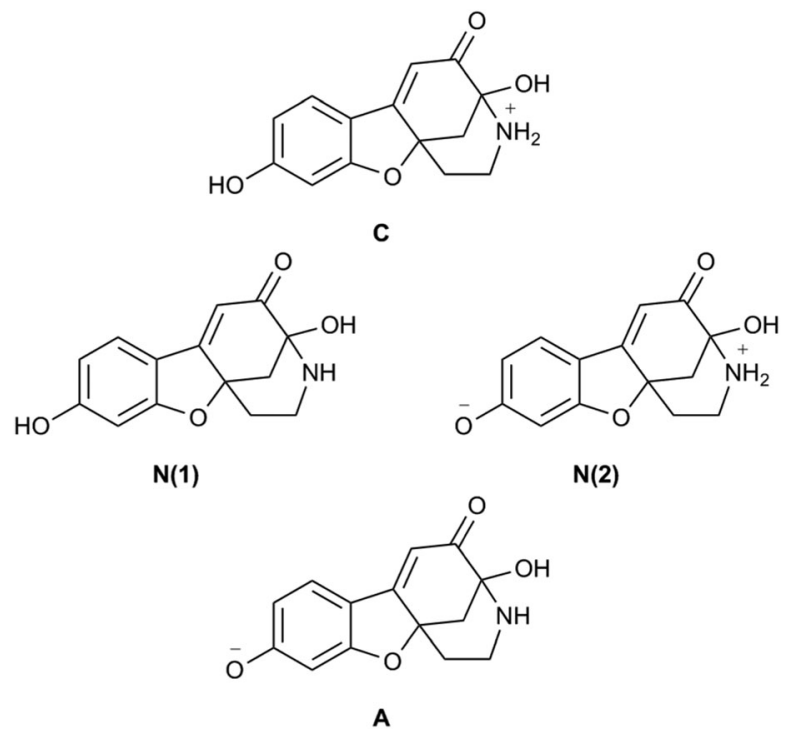

Fig. 9 Cationic $C_{\text {, neutral }} \mathbf{N}(1)$, zwitterionic $\mathbf{N}(2)$ and anionic A forms of azamonardine (2a) in aqueous solution. conciliated if the dominant structure in the emitting singletstate is the zwitterion $\mathbf{N}(2)$, as a result of proton dissociation due to the increase in acidity of the 9-OH group in the excited electronic-state. $^{26}$ Finally, the strong absorption band and intense fluorescence appearing in alkaline solution (Fig. 5) are likely due to the anionic species (A) characterized by a $\mathrm{p} K_{\mathrm{a}}$ value similar to that of 1a. The anion fluorescence decay is clearly biexponential (Table 2), with lifetimes $\approx 1$ and 2 ns, presumably due to some excited-state process, because under the conditions of the lifetime experiments $(\mathrm{pH}=10)$ only one prototropic form is to be found in the ground-state.

\section{Azamonardine electronic transitions and photophysics}

TDDFT methods, as detailed above, were also applied to the neutral, cationic and anionic species of azamonardine (Fig. 9) in water solution, and the most relevant data are listed in Table 4 and in Section S6 of the ESI. $\uparrow$ The computed bond distances and angles of the neutral N(1) and anion species of the aza-compound $\mathbf{2 a}$ are very similar to those of the oxocompound (see Fig. S5 of the ESI + ); in fact, the geometry of the phenol and furanyl rings is virtually identical to that of $\mathbf{1 a}$. The experimental absorption maxima of the cationic $\mathbf{C}$ and neutral $\mathbf{N}(\mathbf{1})$ forms compare well with the computed vertical excitation energies and oscillator strengths. The observed bands can be assigned to the corresponding three opticallyallowed lowest $\left(\pi, \pi^{*}\right)$ transitions listed in Table 4 . The intense absorption of the anion form at $419 \mathrm{~nm}(2.96 \mathrm{eV})$ should be assigned to the $S_{1}\left(\pi, \pi^{*}\right)$ transition in Table 4 ; as noted above the computed energy of this transition is overestimated $(3.3 \mathrm{eV})$ due to the limitations of the PCM model. The cationic species of azamonardine displays a modest fluorescence yield (0.16) consistent with the $\left(\pi, \pi^{*}\right)$ character of the computed lowest excited-state $\mathrm{S}_{1}$ (Table 4 ). The time-resolved emission of this form required a three-exponential function with one negative pre-exponential coefficient (Table 2), indicating that at least a fraction of the emitting species is being produced in the excited state. Solvent-mediated proton-transfer or intramolecular photo-tautomerization reactions in the electronically excitedstate may be responsible for the observed rise-time in the 200 ps time-range.

The high fluorescence yield of the anion form (0.46) is probably related to a distribution of singlet and triplet states similar to that of monardine. The energy separation between $\mathrm{S}_{1}\left(\pi, \pi^{*}\right)$ and $\mathrm{S}_{2}\left(\mathrm{n}, \pi^{*}\right)$ excited-states is relatively large $(0.3 \mathrm{eV})$ preventing interstate coupling, and $\mathrm{T}_{2}-\mathrm{T}_{5}$ states are located at higher energy than $\mathrm{S}_{1}$ (see Table $\mathrm{S} 4$ in the ESI $\dagger$ ). In fact, the $\mathrm{S}-\mathrm{T}$ energy separation would be even higher for the solvent-relaxed $\mathrm{S}_{1}$ state, reducing intersystem crossing de-activation.

The emission properties of the species appearing at $\mathrm{pH} 6$ could only be determined with a large uncertainty, as noted above. Nevertheless, it may be shown that both fluorescence band shape and quantum yield are similar to those of the anion species. These properties are not consistent with the computed singlet-state distribution of the neutral N(1) species presented in Table 4, in which the lowest excited state is an opticallyforbidden $\left(n, \pi^{*}\right)$ state. In fact, these properties might be better 


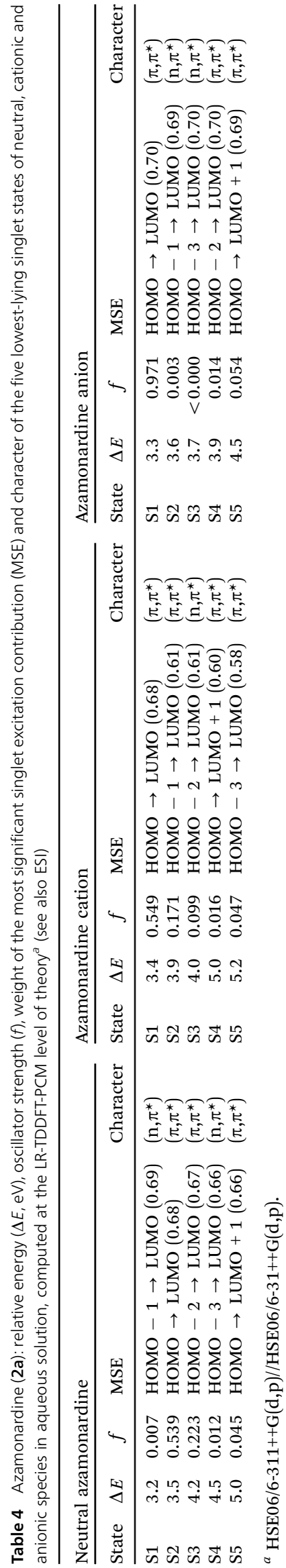

matched by the excited-state distribution of zwitterionic azamonardine, in which the lowest singlet excited-state is of $\left(\pi, \pi^{*}\right)$ character with large oscillator strength. However, it should be recalled that HSE06 functional was not specifically designed for charge transfer states (see ESI $\dagger$ for further details of this assignment). As noted above, the absorption and emission properties of the species appearing at $\mathrm{pH} 6$ might indicate that an excited-state proton-transfer reaction of the absorbing neutral form $\mathbf{N}(\mathbf{1})$ is taking place.

The spectral properties and complex excited-state kinetics of the carboxy-substituted aza compound $\mathbf{2} \mathbf{b}$ are similar to those of the parent 2a, apart from small differences in quantum yield and emission decay. This again reflects the absence of large perturbing effects of the carboxylic group at position 2 . The structure of the $\mathbf{2} \mathbf{b}$ cationic species would be similar to that of 2a shown in Fig. 9, apart from the carboxylic group. In alkaline solution, $\mathrm{pH}>8$, a dianionic species would be present, due to ionization of the 9-OH and 2-COOH groups, as in the oxocompound. Near neutral $\mathrm{pH}$ the absorption spectrum of $\mathbf{2 b}$ is consistent with a non-ionized 9-OH group, while the emission approaches that of $\mathbf{2 b}$ phenolate, as in the unsubstituted compound. However, the assignment of ground-state species is much more uncertain in the present case, due to additional zwitterion forms as $\mathrm{COO}^{-} / \mathrm{NH}^{+}$, and was not investigated further.

\section{Conclusions}

A simple, one-step fluorogenic reaction between hydroxytyrosol and resorcinol in aqueous solution yields the novel oxocine dye 4,9-dihydroxy-1,2-dihydro-4,11a-methanooxocino[4,5- $b]$ benzofuran$5(4 H)$-one (1a, monardine) essentially as a single reaction product. The neutral form of 1a is weakly fluorescent while the anion species, generated by 9-OH group ionization $\left(p K_{\mathrm{a}}=7.2\right)$, shows strongly polarized fluorescence in the blue range with unity quantum yield and single-exponential decay. Based on high-level quantum chemical calculations this switching of the fluorescence yield was interpreted as due to the reversal of $\left(\pi, \pi^{*}\right)$ and $\left(n, \pi^{*}\right)$ lowest singlet excited-states and a crucial change in the triplet-state distribution that accompanies monardine ionization. The convenient spectral properties of the dye are not affected by the presence of an additional reacting group, as shown here for the 2-carboxy compound $\mathbf{1 b}$ that results from the fluorogenic reaction of salvianic acid.

The fluorogenic reaction also takes place with monoamino catechols, as illustrated here with the reaction of dopamine and DOPA to yield the strongly fluorescent aza-analogues of monardine $\mathbf{2 a}$ and $\mathbf{2 b}$, with emission efficiency as high as $\approx 0.5$. The presence of the amino group gives rise to three prototropic species of azamonardine (2a) in the $\mathrm{pH}$ range $3-8$, with different emission efficiency and complex excited-state properties. The fluorogenic reactions of aminocatechols may have useful applications for detecting very low amounts of these important neurochemicals. Overall, the interesting spectroscopic properties of the novel blue fluorophores and the relative simplicity of the fluorogenic reactions in water solution may be of utility in a variety of applications. 


\section{Acknowledgements}

We thank Drs B. Rodriguez and O. Castaño for helpful discussions, and Dr P. Lillo for experimental assistance. PBC thanks Prof. L. M. Frutos for his hospitality during his stay in the RESMOL group at the University of Alcalá. M.L. acknowledges a JAE-Doc Grant from Consejo Superior de Investigaciones Científicas (CSIC). This work was financed by Grants CTQ-2010-16457 (AUA) and CTQ2012-36966 (PBC) of the Min. Ciencia Innov. Spain.

\section{Notes and references}

1 (a) T. J. Fukaminato, J. Photochem. Photobiol., C, 2011, 12, 177; (b) T. Burghardt and K. Ajtai, Biophys. Rev., 2010, 2, 159; (c) P. Kututkura, A. Renn and V. Sandoghar, Nanotechnology, 2009, 5, 113; (d) S. Weiss, Science, 1999, 283, 1676.

2 (a) R. Tomer, K. Khaled, F. Amat and P. J. Keller, Nat. Methods, 2012, 9, 755; (b) H. Kobayashi, M. Ogiwa, R. Alford, P. L. Choyke and Y. Urano, Chem. Rev., 2010, 110, 2620; (c) T. Terai and T. Nagano, Curr. Opin. Chem. Biol., 2008, 12, 515.

3 (a) T. Ha and P. Tinnefeld, Annu. Rev. Phys. Chem., 2012, 63, 597; (b) B. Valeur and M. N. Berberán-Santos, Molecular Fluorescence, Wiley-VCH, Weinheim, 2012; (c) M. Levitus and S. Ranjit, Q. Rev. Biophys., 2011, 44, 1123; (d) R. W. Sinkeldam, N. J. Greco and Y. Tor, Chem. Rev., 2010, 110, 2579.

4 (a) A. A. Souto, A. U. Acuña, J. M. Andreu, I. Barasoaín, M. Abal and F. Amat-Guerri, Angew. Chem., Int. Ed. Engl,, 1995, 34, 2710; (b) E. Quesada, J. Delgado, C. Gajate, F. Mollinedo, A. U. Acuña and F. Amat-Guerri, J. Med. Chem., 2004, 47, 5333; (c) J. M. Saugar, J. Delgado, V. Hornillos, J. R. Luque-Ortega, F. Amat-Guerri, A. U. Acuña and L. Rivas, J. Med. Chem., 2007, 50, 5994.

5 (a) A. U. Acuña and F. Amat-Guerri, in Fluorescence of Supermolecules, Polymers and Nanosystems. Springer Series in Fluorescence, ed. M. N. Berberán-Santos, Springer-Verlag, Berlin, Heidelberg, 2008, vol. 4, pp. 3-20; (b) A. U. Acuña, J. Chem. Educ., 2007, 84, 231.

6 E. Beltrami, M. De Bernardi, G. Fronza, G. Mellerio, G. Vidari and P. Vita-Finzi, Phytochemistry, 1982, 21, 2931.

7 A. U. Acuña, F. Amat-Guerri, P. Morcillo, M. Liras and B. Rodríguez, Org. Lett., 2009, 11, 3020.

8 (a) R. M. Franzini and E. T. Koal, Bioconjugate Chem., 2011, 22, 1869; (b) D. K. Prousty and A. Herrmann, J. Am. Chem. Soc., 2010, 132, 12197.

9 O. Crescenci, A. Napolitano, G. Prota and M. P. Peter, Tetrahedron, 1991, 47, 6243.

10 The trivial name honors N. Monardes' first published description of fluorescence.

11 D. G. Taylor and J. N. Demas, Anal. Chem., 1979, 51, 717.

12 (a) J. R. Lakowicz, Principles of fluorescence spectroscopy, Springer-Verlag, N.Y., 3rd edn, 2006; (b) C. S. Parker, Photoluminescence of solutions, Elsevier Pub. Co., London, 1968; (c) M. Ameloot, M. vandeVen, A. U. Acuña and B. Valeur, Pure Appl. Chem., 2013, 85, 589.

13 A. Albert and E. P. Serjeant, The determination of ionization constants, Chapman and Hall, London, 1984.

14 H. T. K. Britton and R. A. Robinson, J. Chem. Soc., 1931, 1556.

15 (a) J. Heyd, G. E. Scusseria and M. Ernzerhof, J. Chem. Phys., 2003, 118, 8207; (b) J. Heyd and G. E. Scusseria, J. Chem. Phys., 2004, 120, 7274; (c) J. Heyd, G. E. Scusseria and M. Ernzerhof, J. Chem. Phys., 2006, 124, 219906.

16 J. Tomasi, B. Mennucci and R. Cammi, Chem. Rev., 2005, 105, 2999.

17 M. Cossi and V. Barone, J. Chem. Phys., 2001, 115, 4708.

18 M. J. Frisch, G. W. Trucks, H. B. Schlegel, G. E. Scuseria, M. A. Robb, J. R. Cheeseman, G. Scalmani, V. Barone, B. Mennucci, G. A. Petersson, H. Nakatsuji, M. Caricato, X. Li, H. P. Hratchian, A. F. Izmaylov, J. Bloino, G. Zheng, J. L. Sonnenberg, M. Hada, M. Ehara, K. Toyota, R. Fukuda, J. Hasegawa, M. Ishida, T. Nakajima, Y. Honda, O. Kitao, H. Nakai, T. Vreven, J. A. Montgomery Jr., J. E. Peralta, F. Ogliaro, M. Bearpark, J. J. Heyd, E. Brothers, K. N. Kudin, V. N. Staroverov, R. Kobayashi, J. Normand, K. Raghavachari, A. Rendell, J. C. Burant, S. S. Iyengar, J. Tomasi, M. Cossi, N. Rega, J. M. Millam, M. Klene, J. E. Knox, J. B. Cross, V. Bakken, C. Adamo, J. Jaramillo, R. Gomperts, R. E. Stratmann, O. Yazyev, A. J. Austin, R. Cammi, C. Pomelli, J. W. Ochterski, R. L. Martin, K. Morokuma, V. G. Zakrzewski, G. A. Voth, P. Salvador, J. J. Dannenberg, S. Dapprich, A. D. Daniels, Ö. Farkas, J. B. Foresman, J. V. Ortiz, J. Cioslowski and D. J. Fox, Gaussian 09, Revision C.1, Gaussian, Inc., Wallingford, CT, 2009.

19 T. J. V. Prazeres, A. Fedorov, S. P. Barbosa, J. M. G. Martinho and M. N. Berberan-Santos, J. Phys. Chem., 2008, 112, 5034.

20 (a) B. N Matto, Z. Phys. Chem., Neue Folge, 1957, 12, 232; (b) T. Moriya, Bull. Chem. Soc. Jpn., 1983, 56, 6.

21 E. V. Anslyn and D. A. Dougherty, Modern Physical Organic Chemistry, University Science Books, Sausalito, 2006.

22 F. P. Vánia, P. Remón, D. Collado, J. Andréasson, E. PérezInestrosa and U. Pischel, Org. Lett., 2011, 13, 5572.

23 F. H. Allen, O. Kennard, D. Watson, L. Brammer, A. G. Orpen and R. Taylor, J. Chem. Soc., Perkin Trans. 2, 1987, S1-S19.

24 W. A. Wassan and E. C. Lim, J. Chem. Phys., 1978, 68, 433. 25 (a) S. Lower and M. ElSayed, Chem. Rev., 1966, 66, 199; (b) M. ElSayed, J. Chem. Phys., 1963, 38, 2834.

26 (a) J. S. Kleck, A. N. Bader, F. Ariese and C. Gooijer, Rev. Fluoresc., 2009, 4, 271; (b) N. Agmon, J. Phys. Chem. A, 2005, 109, 13; (c) L. G. Arnaut and J. S. Formosinho, J. Photochem. Photobiol., A, 1993, 75(1), 21; (d) M. R. Nimlos, D. F. Kelly and E. R. Bernstein, J. Phys. Chem., 1987, 91, 6610; (e) P. J. Thistlewaite and P. J. Corkill, Chem. Phys. Lett., 1982, 85, 317. 